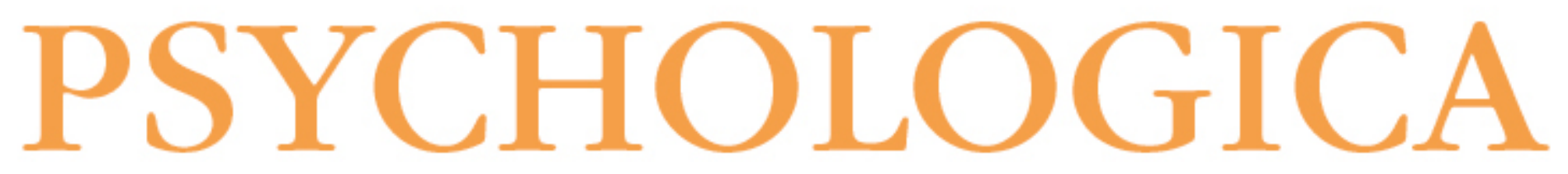

\title{
O papel dos processos neurobiológicos na terapia de casal cognitivo- comportamental
}
Autor(es):
Dattilio, Frank M.
Publicado por: Imprensa da Universidade de Coimbra
URL
persistente:
URI:http://hdl.handle.net/10316.2/5475
DOI:
DOI:http://dx.doi.org/10.14195/1647-8606_51_17
Accessed : $\quad$ 26-Apr-2023 12:32:35

A navegação consulta e descarregamento dos títulos inseridos nas Bibliotecas Digitais UC Digitalis, UC Pombalina e UC Impactum, pressupõem a aceitação plena e sem reservas dos Termos e Condições de Uso destas Bibliotecas Digitais, disponíveis em https://digitalis.uc.pt/pt-pt/termos.

Conforme exposto nos referidos Termos e Condições de Uso, o descarregamento de títulos de acesso restrito requer uma licença válida de autorização devendo o utilizador aceder ao(s) documento(s) a partir de um endereço de IP da instituição detentora da supramencionada licença.

Ao utilizador é apenas permitido o descarregamento para uso pessoal, pelo que o emprego do(s) título(s) descarregado(s) para outro fim, designadamente comercial, carece de autorização do respetivo autor ou editor da obra.

Na medida em que todas as obras da UC Digitalis se encontram protegidas pelo Código do Direito de Autor e Direitos Conexos e demais legislação aplicável, toda a cópia, parcial ou total, deste documento, nos casos em que é legalmente admitida, deverá conter ou fazer-se acompanhar por este aviso. 
NÚMERO 51

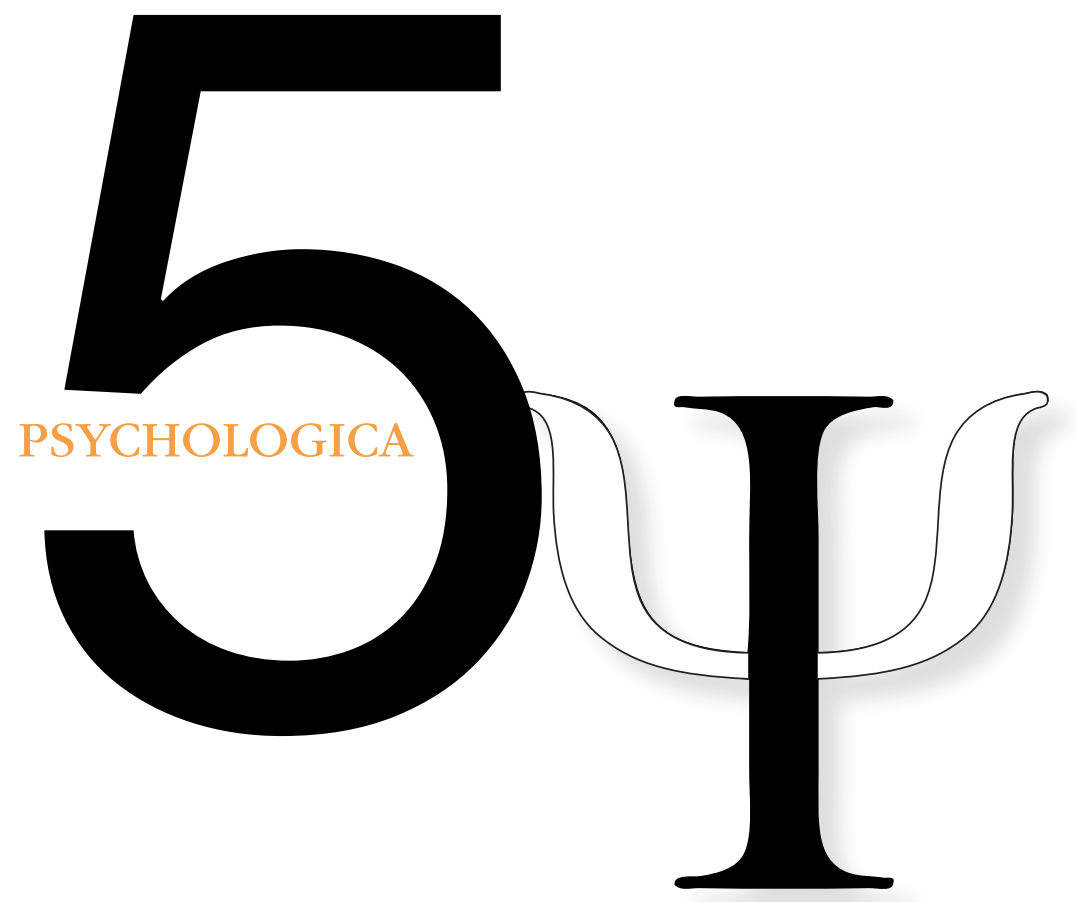

IMPRENSA DA UNIVERSIDADE DE COIMBRA

FACULDADE DE PSICOLOGIA E DE CIÊNCIAS DA EDUCAÇÃO DA UNIVERSIDADE DE COIMBRA 


\title{
O papel dos processos neurobiológicos na terapia de casal cognitivo-comportamental
}

\author{
Frank M. Dattilio'
}

Recentemente, a literatura especializada sobre as relações de casal tem-se focado nos efeitos que a genética e a neurobiologia têm nas dinâmicas interaccionais. Tem sido dada uma atenção especial à forma como os padrões emocionais e comportamentais são afectados pelos proponentes neurobiológicos.

Este artigo expõe uma revisão breve da literatura sobre este tópico e apresenta exemplos breves de casos ilustrativos de que considerar os processos neurobiológicos, em conjunto com as técnicas cognitivo-comportamentais, pode ser um componente crucial para ajudar alguns casais a lidar com problemas relacionais.

Na discussão, destacam-se considerações futuras para a investigação e desenvolvimento futuros nesta área.

PALAVRAS-CHAVE: Processos neurobiológicos; regulação emocional; genética, amígdala.

\section{Introdução}

Recentemente, tem-se dado uma atenção crescente ao efeito que a genética e a neurobiologia têm nas relaç̃oes interpessoais. O campo emergente da Neuropsicobiologia oferece-nos um novo conhecimento sobre como os padrões emocionais e comportamentais se desenvolvem nas relações íntimas (Schore, 1994, 2001, 2003). Algum deste trabalho tem sido também integrado com a Teoria da Vinculação quando aplicada à terapia de casal, colocando a ênfase na regulação de afecto diádico (Goldstein \& Thau, 2004; Lewis, Amini, \& Lannon, 2002). É possível que, compreendendo a forma como o sistema nervoso de cada parceiro é influenciado pelas "reverberações emocionais" activadas nas interacções diádicas, os casais

1 Harvard Medical School.

Frank M. Dattilio, Ph.D, ABPP, Departamento de Psiquiatria da Harvard Medical School, Boston, MA. Toda a correspondência deve ser enviada para o autor: frankdattilio@cs.com.

Nota do Autor: Partes deste artigo foram retiradas de Dattilio, F. M. (2010). Cognitive-behavior therapy with couples and families: A comprehensive guide for clinicians. New York: Guilford, e foram reproduzidas com permissão do autor. 
possam trabalhar para criar uma maior sintonia emocional e estabelecer uma base mais segura na sua relação com o cônjuge (Lewis et al., p. 131).

A investigação recente tem também apoiado as hipóteses de que as relações românticas podem envolver um estado motivacional tão essencial como a fome e a sede. Um estudo em particular, conduzido por Artur Aron e colaboradores, demonstrou que certas áreas ricas em dopamina se activam quando pensamos nos nossos parceiros românticos, como indicam os resultados da ressonância magnética imagética funcional (RMIf) (Aron, Fisher, Mashek, Strong, \& Brown, 2005). Tais regiões do cérebro, como é o caso da área tegmental ventral (ATV), são vistas como o sistema de motivação e recompensa e parecem ser activadas sempre que os indivíduos obtêm alguma coisa que desejam intensamente. Os participantes do estudo de Aron et al. apresentaram uma variedade de diferentes emoções enquanto olhavam atentamente para os seus parceiros. A actividade cerebral mostrou igualmente uma diversidade de padrões de activação na amígdala, frequentemente referida como o centro emocional (p. 335).

No seu bem conhecido livro The Developing Mind, Daniel Siegel (1999) oferece um excelente sumário de como o cérebro influencia as nossas relações e do impacto que as relações têm na nossa neuroquímica. A investigação sugere que a interacção entre estes dois elementos molda o que somos como seres humanos. O resto, naturalmente, é influenciado pelas nossas experiências ambientais. Siegel dedica uma atenção considerável ao sistema límbico do cérebro, que se encontra localizado centralmente e consiste em regiões conhecidas como o córtex orbital frontal, o cíngulo anterior e a amígdala. Estas regiões desempenham um papel significativo na coordenação da actividade das estruturas cerebrais altas e baixas e acredita-se que medeiam as emoções, as motivações e os comportamentos orientados para objectivos. De facto, o cérebro límbico tem sido por vezes referido como o "cérebro emocional" (Atkinson, 2005; Pessoa, 2008). Esta região também aloja as conexões neuronais para todas as zonas do neocórtex, a parte do cérebro mais recentemente desenvolvida que regula, entre outras funções, a percepção e o comportamento. As estruturas límbicas também facilitam a integração de uma diversidade de processos mentais primários muito importantes para o funcionamento humano, tais como a avaliação do significado, o processamento da experiência social e a regulação das emoções. Esta informação sugere que existe muito mais relacionado com a bioquímica e o seu impacto nas relações do que os investigadores anteriormente pensavam.

Por vezes, o facto de terapeutas e clientes considerarem o sistema límbico pode ser um factor crucial para fazer progressos no tratamento. Ainda que o cérebro esteja geneticamente programado para funcionar de uma certa forma, este não age isoladamente das experiências do indivíduo. A neurobiologia e as experiências de vida interagem de tal modo que determinadas predisposições biológicas são capazes de 
criar experiências características que podem contribuir fortemente para o sucesso de uma relação. Uma vez que a mente do indivíduo se desenvolve na interface de processos neurofisiológicos e relações interpessoais, as experiências relacionais específicas têm consequentemente uma influência dominante na actividade cerebral. Existe, inclusivamente, evidência que sugere que os sistemas límbicos de alguns individuos estão geneticamente estruturados para se desenvolver de forma diferente de outros (LeDoux, 2003). Isto explicaria a razão por que certas pessoas se emocionam mais facilmente que outras. Por exemplo, a investigação sugere que o sistema límbico das mulheres difere do dos homens, dai que elas chorem mais facilmente e mostrem emoções de forma distinta dos homens (Siegel, 1999). Curiosamente, no entanto, em muitas culturas, os homens têm, tradicionalmente, demonstrado intolerância em relação a este atributo, o que tem sido registado ao longo do tempo (Coontz, 2005). Por conseguinte, tais informações baseadas em evidências podem servir para dissipar a enraizada crença errónea dos homens de que as mulheres apenas choram para os manipular e obter o que desejam. Esta é uma distorção cognitiva que parece ser, em parte, erradamente fundamentada.

No seu recente livro The Female Brain, Louann Brizendine (2006) refere investigação realizada na Universidade do Michigan, mostrando que as mulheres usam ambos os hemisférios do seu cérebro para responder às experiências emocionais, enquanto os homens usam apenas um hemisfério (Wagner \& Phan, 2003). Foi ainda determinado que as conexões entre os centros emocionais do cérebro são igualmente mais activas e extensas nas mulheres (Cahill, 2003). Isto possivelmente explica por que é que as mulheres normalmente recordam mais vivamente acontecimentos emocionais, tais como discussões, e os retêm durante mais tempo do que os homens.

\section{O Papel da Amígdala}

A amígdala é uma das áreas do cérebro mais frequentemente estudadas na literatura científica, particularmente no que se relaciona com a emoção (LeDoux, 1996). Os estudos têm analisado como o início de uma avaliação conduz a subsequentes enviesamentos perceptuais que reforçam a natureza da avaliação inicial. O fluxo da activação dos circuitos cerebrais inicia um processo alargado de reunião de várias activações que, então, preparam o indivíduo, ou organismo, para uma determinada resposta. A amígdala responde à representação visual inicial (e.g., um cão a ladrar) enviando sinais de volta para a mesma e, até, para camadas anteriores do sistema de processamento visual, produzindo depois uma orientação inicial do aparelho atencional e perceptual do cérebro (Siegel, 1999). O que é particularmente interessante é que a amígdala pode rapidamente enviesar 
o aparelho perceptual, interpretando, assim, erradamente quaisquer estímulos (e.g., perigoso vs. seguro). Tudo isto ocorre em segundos, sem qualquer dependência da percepção consciente. Portanto, se um cônjuge que tenha sido criado num ambiente familiar com um pai abusador se torna um alvo de abuso físico ou psicológico pelo parceiro, ele ou ela, pode, naturalmente, tornar-se altamente sensibilizado, fisiologicamente, através da amígdala. Consequentemente, qualquer conflito que ocorra em situações familiares, e que se assemelhe ao abuso anterior experienciado enquanto criança, seria automaticamente activado pela amigdala. Isto aconteceria independentemente de intervenções mediacionais do tipo cognitivo, comportamental ou emocional. Efectivamente, dependendo da intensidade e da magnitude do abuso anterior, a amígdala poderá ter sido fisiologicamente aprumada ou programada para responder de um modo "reactivo" ou "hipersensível", devido à dominância da química corporal ao longo do tempo.

Este conceito tem sido desenvolvido por Candace Pert, professora de Fisiologia Celular da Universidade de Georgetown e especialista em farmacologia peptídica. Pert e colaboradores argumentaram que corpo e mente estão em constante comunicação entre si, através de químicos orgânicos conhecidos como peptídeos. Esta teoria sugere que a memória pode ser acedida em qualquer local da rede receptora do peptídeo, desde o cérebro e os circuitos até aos órgãos internos, incluindo a superfície da pele. Pert refere resultados empíricos de investigações que indicam que os neuropeptídeos e os seus receptores, conhecidos como receptores opiáceos, formam uma rede de informação no corpo que influencia tanto a cognição como a emoção (Pert, Ruff, Weber, \& Herkenham, 1985; Pert \& Snyder, 1973). Este conceito será discutido posteriormente, dado que se pode aplicar à extensão e conceito de esquema em geral (Dattilio, no prelo).

Aprender a valorizar a linguagem biofisiológica dos nossos cônjuges e membros da família e o modo como esta afecta a emoção e o comportamento é extremamente importante. Como exemplo, temos as reacções viscerais que os casais e membros da família mostram uns aos outros nas interacções do dia-a-dia. Alguns aspectos não verbais da comunicação, tais como contacto visual, tom e volume da voz, e certos movimentos corporais, como expressões faciais e postura, reflectem actividade do hemisfério direito, que é responsável pela emoção e pelo processamento implícito. Isto tornar-se-ia importante quando certos movimentos corporais são feitos enquanto um dos membros do casal está a pensar sobre o que está a ser dito, mas são interpretados pelo outro elemento do casal como sendo um gesto de irritação, quando na realidade são um resultado do processamento do material pelo hemisfério direito. Por conseguinte, a conotação negativa atribuída pode não ser correcta para explicar a manifestação comportamental. Educar os cônjuges ou membros da família sobre como o cérebro processa determinada informação 
e como, posteriormente, a manifesta é um instrumento útil para melhorar as relações e pode ser crucial para melhorar a sua interacção.

Na mesma linha, o tom de voz do cônjuge ou familiar que não corresponde à sua expressão facial de raiva pode sugerir uma conexão pobre com as suas emoções. Um excelente exemplo deste aspecto é ilustrado no diálogo seguinte.

Neste caso particular, um casal veio a uma sessão terapêutica após ter tido uma discussão muito intensa. A discussão começou porque a esposa se esqueceu de enviar a confirmação sobre a participação de ambos num evento social importante. Quando chegaram à recepção, no dia do evento, não havia uma mesa reservada para os dois e tornou-se claro que, dado não ter sido enviada a resposta a confirmar a presença, eles não foram incluídos na lista de convidados. Este erro causou bastante embaraço ao casal e o marido ficou furioso, referindo que a esposa era descuidada e que nunca cumpria as suas responsabilidades. Este erro causou muita tensão na relação, levando a uma intensa discussão sobre a noção de descuido repetido e sobre a falta de atenção aos detalhes por parte da esposa.

No decurso de sessão terapêutica, enquanto o marido embarcou num discurso aceso sobre como se sentiu "farto e zangado" com esta situação, e com muitas outras semelhantes, o comportamento da esposa indicava que se encontrava tensa. O seu maxilar estava cerrado e falava num tom de voz muito baixo, dizendo que lamentava e que compreendia a razão pela qual o marido estava aborrecido. No entanto, ao mesmo tempo, o seu comportamento comunicava algo muito diferente. Uma veia sobressaía da testa e a cara começava a ficar vermelha. Quando Ihe foi perguntado se se sentia ou não embaraçada, ela negou, mas depois declarou que compreendia o porquê de o marido estar zangado e que não o culpava. O estranho nesta troca [de diálogo] foi que o tom de voz da esposa não correspondia nem às suas expressões faciais, nem à sua linguagem corporal. Quando Ihe foi chamada a atenção para o facto de mostrar todos os sinais de estar furiosa e preparada para saltar do seu lugar, e ainda que as suas palavras eram incongruentes com os seus comportamentos, ela mostrou-se muito surpreendida.

Esta mulher, naquele momento, parecia incapaz de ligar as suas emoções aos seus pensamentos espontâneos. O terapeuta deu à mulher um espelho para que ela pudesse prestar atenção às suas expressões faciais. Foi-Ihe também pedido para tocar no seu maxilar inferior e na área mandibular, bem como no sítio da testa onde a veia estava saliente. Quando Ihe foi pedido para tocar no próprio rosto, ela ficou chocada com a tensão do seu corpo. Foi-lhe então pedido para tentar entrar em contacto com a sua cólera, ao invés do que havia expressado anteriormente, de lamentar o sucedido. Ela foi finalmente capaz de revelar que estava realmente zangada com o marido, porque ele raramente assumia a responsabilidade por tarefas como responder a "respostas de confirmação" e que deixava toda a responsabilidade 
para ela. Ela confirmou que Ihe tinha sido realmente difícil sentir-se abertamente zangada, porque o marido tinha adoptado sempre uma postura mais agressiva, a qual ela já sentiu tê-la inibido no passado. Foi explicado à esposa que era óbvio que a cólera não era uma emoção que ela se permitia experienciar facilmente. Em vez disso, ela quase exprimia o que pode ser cunhado como "formação da reacção" de vergonha e culpa em relação aos seus sentimentos de raiva. Foi-lhe ainda indicado que este aspecto poderia ter alguma coisa a ver com o facto de as suas distracções terem continuado porque ela se sente realmente muito zangada com o marido, e que estes podem ser vistos como uma resposta passivo-agressiva ao ressentimento que ela tem em relação ao marido.

O diálogo acima referido tornou-se um ponto de referência que foi usado na terapia com este casal para debater sentimentos, que eram expressos de forma não verbal, particularmente através de gestos, expressões faciais e sinais visuais. O conceito de estar atento à comunicação não verbal do outro foi extremamente poderoso para ajudá-los a sentir a incongruência entre as suas expressões verbais e as manifestações comportamentais, e a perceber a forma como estes aspectos influenciavam negativamente a sua interacção. Enquanto aprendem a valorizar o equilíbrio e a harmonia nas relações, os casais podem também aprender a processar a dor dos períodos de comunicação difícil e a ter em consideração que o conflito é uma parte normal de qualquer relação de casal e um reflexo das diferenças entre dois parceiros independentes (Gottman, 1991).

Na mesma linha, o comportamento não verbal pode igualmente ter um significado diferente da forma como é interpretado. Por exemplo, durante uma sessão de terapia familiar, os pais expressavam raiva em relação à sua filha na pré-puberdade, porque esta revirava os olhos sempre que eles a questionavam sobre o regresso a casa a pós a hora obrigatória de regresso. Os pais repreendiam-na pela "expressão de esperteza", o que a filha negava estar a fazer. A filha alegava não ter consciência disto e insistia que não estava a ser nada "esperta" e que tinha feito isto durante a vida inteira. Quando foi explicado aos pais que a tendência da filha para "revirar os olhos" para a direita talvez pudesse indicar que ela estava a usar o hemisfério esquerdo para processar as palavras que estavam a ser ditas, a situação passou a ser vista de um modo totalmente diferente. É inteiramente possível que o comportamento da filha fosse ou não, em parte, uma "reacção impertinente", mas foi importante que a família compreendesse que algumas reacções não podem ser sempre interpretadas como o que parecem à primeira vista.

O uso de técnicas cognitivas, como a inundação do sentimento positivo sugerida por Gottman (1999), envolve ensinar as pessoas a considerar a relevância da resposta da sua amígdala à situação actual e ao trauma passado, tal como no caso de abuso anteriormente mencionado. O mecanismo inicial de activação é, 
então, modificado pelo uso de uma estratégia do tipo “falar consigo próprio", para reduzir a reacção fisiológica. Tais técnicas imagéticas podem ser úteis para fazer a amígdala "suspirar de alívio" por não ter de responder da forma para que estava programada. Por conseguinte, mesmo que a resposta fisiológica de um indivíduo a um estímulo particular não possa ser completamente mudada, a resposta à activação inicial pode ser modificada para se tornar mais flexível.

As técnicas de terapia cognitiva podem servir para reduzir a intensidade do processo de activação fisiológica, bem como para reestruturar a distribuição dos grupos neuronais. Isto pode influenciar a reactivação do córtex, que controla o raciocínio abstracto. Isto permite depois que tenha lugar o processo metacognitivo de auto-reflexão e controlo de impulsos. Tal intervenção pode conduzir a uma maior tolerância dos níveis de activação, que anteriormente podem ter sido demasiado esmagadores. Fortalecer a capacidade cortical metacognitiva pode igualmente abrir caminho para maior acesso à tolerância durante situações emocionalmente pesadas.

Períodos prolongados de inundação de emoções sem um processo mediador eficaz podem resultar em estados prolongados de desorganização (Siegel, 1999). Por vezes, um fluxo de emoções precisa de ser compreendido como um problema de processamento. Isto é, podemos sentir-nos frequentemente esmagados com emoções, tal como quando um cano de água rebenta e expele tudo à sua volta. Ensinar técnicas, tais como a ventilação e/ou a regulação emocional, pode ser fundamental para casais em sofrimento. Uma respiração profunda e o relaxamento muscular progressivo podem também ajudar os indivíduos a reduzir os circuitos de energia e a tensão dos seus corpos. O biofeedback pode ainda ser utilizado para ensinar os casais e membros da família a regular estes processos (Dattilio, 2010).

A metacognição inclui ainda a consciência de que as emoções influenciam o pensamento e a percepção, e de que nós podemos ser capazes de experienciar duas emoções aparentemente conflituais sobre a mesma pessoa ou experiência (Siegel, 1999).

\section{Cognição vs. Emoção}

Surgiu uma controvérsia interessante sobre o modo como a cognição e a emoção se influenciam mutuamente. Durante muitos anos, assumiu-se que a cognição era o organizador primário da experiência humana no cérebro (LeDoux, 2000). Efectivamente, este aspecto funcionou como a base de muitas teorias de psicoterapia (Beck, 1967, Kelly, 1955). A terapia cognitiva assentava na premissa de que existe uma interacção recíproca entre cognição, humor e comportamento, e que 
os pensamentos influenciam fortemente o humor e o comportamento (Beck et al., 1979). Uma afirmação do filósofo grego estóico Epictetus é frequentemente citada pelos terapeutas cognitivos: "o que mais perturba os seres humanos não são as coisas em si, mas a sua interpretação das coisas” (Epictetus, M5 [sem data]). Por esta razão, muita da revolução cognitiva focou-se nos processos cognitivos como tendo uma profunda influência no humor e no comportamento do indivíduo.

A revolução cognitiva foi impulsionada por descobertas prévias sobre o cérebro e as suas várias áreas, particularmente o neocórtex, que facilita a capacidade para pensar em termos abstractos. O neocórtex tem três vezes o tamanho do centro límbico (frequentemente designado por cérebro emocional). A descoberta do neocórtex estimulou o pressuposto de que o pensamento, por conseguinte, deve ser predominante sobre a emoção e tem uma influência central no comportamento humano. O neocórtex, especificamente, permite aos seres humanos articular e envolver-se no pensamento simbólico, bem como no pensamento categorial abstracto. Por esta razão, pressupôs-se que esta área do cérebro seria responsável pela maioria da organização da experiência humana. Consequentemente, seria de esperar ver muitas mais conexões neuronais do cérebro "pensante" para o cérebro emocional do que no sentido inverso (Atkinson, 2005).

No entanto, durante as últimas décadas, a literatura científica tem pedido a reformulação desta compreensão do neocórtex, particularmente à luz das descobertas que sugerem que o cérebro emocional domina a organização da função humana. A investigação recente indica que as conexões neuronais dos sistemas emocionais aos sistemas cognitivos parecem ser mais fortes que as conexões que existem dos sistemas cognitivos aos emocionais (Le Doux, 1996). LeDoux verificou que as projecções neuronais dos sistemas do cérebro emocional (límbico) ligam-se a todas as outras partes do cérebro e influenciam cada fase do processamento cognitivo. Contudo, nem todos os processos cognitivos projectam para os centros emocionais. Este aspecto sugeria a existência de um circuito unidireccional, o qual conduziu LeDouz à ideia de que a emoção pode, de forma clara e primária, influenciar aquilo em que os indivíduos se focam, através das suas interpretações do que percepcionam. Isto é também a poiado pela descoberta de que as emoções estão intrinsecamente ligadas a mecanismos de avaliação-activação em ambos os hemisférios do cérebro e influenciam todos os aspectos da cognição, desde a percepção à tomada de decisão (Siegel, 1999).

Muitas das teorias cognitivas estão enraizados na crença de que o pensamento lógico é a forma mais eficaz de lidar com as situações, particularmente as que envolvem decisões importantes. Consequentemente, mediar o conteúdo emocional que possa interferir no pensamento racional sempre foi algo fortemente encorajado pelos terapeutas cognitivos (Beck, 1967; Beck et al., 1979). No entanto, 
alguns investigadores, como Damásio (1994), verificaram que os indivíduos que têm uma maior capacidade de afastar as suas emoções do processo de tomada de decisão e de se focar apenas em pensamentos racionais tomam, na realidade, decisões péssimas (Damásio, 2001). Damásio argumenta que o cérebro humano está estruturado de tal modo que respostas subtis podem frequentemente criar processos cognitivos enviesados sem que o indivíduo pensante possa estar consciente disso, criando, assim, a possibilidade de que o indivíduo pensa que está a ser perfeitamente racional (Damásio, 1999). Este argumento é apoiado, em parte, por estudos que mostram que os indivíduos estão, muitas vezes, inconscientes da experiência de emoções, mesmo quando a evidência fisiológica da resposta galvânica da pele ou outros tipos de manifestações físicas o demonstram (Goleman, 1995; LeDoux, 1996). Estes dados contrariam a crença de que é neurologicamente impossivel para a emoção ser activada sem a consciência do indivíduo. LeDoux (1994, 2000) levou este resultado mais longe, explicando como o cérebro cria memórias sobre acontecimentos emocionais que um individuo experiencia durante a vida, referindo-se-Ihe como memória emocional. Este aspecto torna-se importante no trabalho com casais e famílias, particularmente porque a memória emocional parece ser o centro de muitos dos conflitos que vemos nos casais e famílias.

Os terapeutas cognitivos continuam a argumentar, no entanto, que as emoções se fervem lentamente abaixo do limiar da consciência, mas que são activadas neurologicamente através do pensamento consciente. Dado que os pensamentos são frequentemente espontâneos, uma pessoa poderá não reconhecer imediatamente o impacto dos seus pensamentos ou das suas emoções (Beck, 1967; Gardner, 1985).

Como resultado dos seus estudos, Damásio sugeriu que uma definição melhor do que significa ser racional inclui a noção de que a racionalidade depende da capacidade para experienciar a emoção, quer na reacção a situações presentes, quer também na recordação de situações passadas e na visualização de situações futuras (Atkinson, 2005).

Compreender a neurociência da emoção é importante no processo de terapia familiar porque o cérebro contribui substancialmente para a capacidade de o indivíduo funcionar e para a própria consciência dos seus estados internos. O objectivo não é dar armas aos membros da família que querem culpar a sua química cerebral pelas suas acções. Mais exactamente, aumentar a nossa consciência sobre os nossos estados internos pode, nesta sequência, incitar certas funções cerebrais a tornar-se mais activas e, deste modo, ajustar o raciocínio e a emoção. No seu livro Emotional Intelligence in Couples Therapy, Atkinson (2005) sugere que o conceito de consciência de estados internos pode ser extremamente útil para capacitar os clientes a mudar os circuitos cerebrais isolados e defensivos que geram raiva e medo, de forma a ligarem-se a circuitos reparadores que medeiem a prestação 
de cuidados e a tristeza. Este autor propõe que dar uma atenção imediata e aprofundada aos sistemas neuronais defensivos do cliente permite ao terapeuta treinar os clientes simpática e respeitosamente, através de estados cerebrais interactivos, até que os clientes se sintam seguros o suficiente para mudar para estados mais vulneráveis (p. 32). Atkinson vê o sentimento interno de segurança como o "pivô de mudança para casais". A amígdala apenas se desliga quando um indivíduo já não se sente ameaçado pelo seu(sua) parceiro(a). Isto, por sua vez, irá influenciar o sistema de alarme interno, conferindo aos clientes a liberdade de mudar verdadeiramente para um estado neuronal promotor da intimidade.

As estratégias cognitivo-comportamentais são uma parte importante da terapia, particularmente na influência sobre a estrutura do cérebro que armazena o córtex pré-frontal. A principal diferença, porém, é que, em vez de usar a cognição para controlar o cérebro límbico, poderá ser mais eficaz colocá-lo a trabalhar através da amigdala e gradualmente relaxar as suas defesas. Atkinson tem claramente razão quando sugere que uma perspectiva mais abrangente da interacção cognitivo-emocional nos circuitos cerebrais é central para facilitar a mudança. No entanto, para muitos, aceder a tais processos pode ser mais prático através de processos cognitivos e/ou comportamentais.

O caso seguinte é um exemplo de como ter atendido à questão do processamento neurobiológico foi crucial para ajudar o casal a descrever os problemas da sua relação.

\section{Exemplo de um caso}

O Luís e a Maria estavam casados há 18 anos quando procuraram tratamento. Tinham três filhos adultos, um dos quais ainda vivia em casa. O casal referiu experienciar uma grande quantidade de tensão na relação, devido à crença da Maria de que o Luís simplesmente não a compreendia, especialmente quando ela Ihe tentava expressar os seus sentimentos. O Luís tinha trabalhado a tempo inteiro na indústria de pesca e tinha-se reformado recentemente, apesar de ainda estar na casa dos 50 anos. A companhia onde trabalhava tinha-lhe oferecido um pacote de reforma antecipada que o Luís disse "não poder recusar". A Maria era contabilista e deixara de trabalhar fora de casa assim que os filhos nasceram. Voltou mais tarde ao trabalho, quando os filhos atingiram a idade escolar. É a partir deste momento que o casal menciona o agravamento dos problemas na relação.

Existia também tensão relativamente à crença do Luís de que os amigos e a vida social da Maria eram uma prioridade mais importante do que a sua relação. O Luís sentia falta de companheirismo no casamento e uma falta grave de comunicação entre si e a esposa. Como resultado, o Luís afastou-se da Maria e os dois comunicavam 
cada vez menos. A Maria também se queixou de que quaisquer sentimentos que expressasse ao Luís, eram por ele distorcidos e transformados noutra coisa qualquer, o que era extremamente frustrante para ela. Sempre que a Maria tentava clarificar as suas afirmações, o Luís ficava na defensiva e resguardava-se atrás de um muro de silêncio. A Maria acreditava que o Luís interpretava mal o que ela lhe dizia, numa tentativa deliberada de a sabotar. A Maria brincava com frequência: "penso que ele passou anos demais no mar", "ele está enjoado". O Luís insistia que compreendia o que a Maria Ihe estava a dizer, mas o seu comportamento subsequente sugeria que ele não tinha compreendido e, consequentemente, discutia com ela. A Maria declarou que quando "o Luís não me ouve, ele apenas preenche incorrectamente os espaços em branco - tal como uma criança pequena". Ela também sentia que era punida pelo Luís por expressar os seus sentimentos.

À medida que o tratamento avançava, o foco foi direccionado para o treino básico de comunicação. Logo se tornou claro, no entanto, que existia algo muito errado na forma como o Luís processava as afirmações verbais da Maria. A Maria e o Luís começaram a comunicar através de mensagens de texto, porque parecia que eles se davam melhor através deste método do a que falar cara a cara e a lidar com as emoções um do outro.

À medida que a terapia progredia, tornou-se cada vez mais óbvio que parecia existir um problema evidente com o processamento auditivo do Luís. Ele abanava frequentemente a cabeça em sinal de afirmação quando a Maria falava com ele mas, mais tarde, agia como se nunca tivesse ouvido uma palavra do que ela tinha dito. Habitualmente, o Luís vinha às sessões terapêuticas com uma bengala. Ele referiu ter desenvolvido uma condição neurológica conhecida como degeneração cerebelar. Esta condição envolve uma deterioração da motricidade fina corporal, a qual inibe a capacidade para coordenar eficazmente o funcionamento físico. Um sintoma menos comum desta doença inclui dificuldades no processamento cognitivo. Algumas investigações verificaram que a ataxia espino-cerebelar é hereditária e pensava-se ser o sintoma mais predominante. Vários casos desta doença também referiram perturbações do humor associadas, bem como dificuldades de concentração e de memória. Em alguns casos, as vítimas desta doença referiam experienciar alexitimia, a incapacidade para recordar ou transmitir emoção através da expressão verbal. O Luís finalmente submeteu-se a uma avaliação neuropsicológica, cujos resultados mostraram evidência de défices no seu processamento auditivo e nas suas competências de integração sensorial. Esta nova informação permitiu ao Luís e à Maria compreender que parte da dificuldade que o Luís sentia não era deliberada como a Maria imaginava mas, muito provavelmente, era um sintoma da sua degeneração cerebral.

Este novo conhecimento teve um efeito enorme na forma como a Maria respondia à dificuldade do seu marido. O Luís também pareceu muito menos frustrado 
quando este aspecto foi clarificado, ficando, contudo, obviamente perturbado devido ao facto de isto constituir um sinal de deterioração progressiva. Apesar de a Maria referir que o Luís tinha sido sempre assim desde que se conheceram, esta dificuldade tornou-se claramente pior ao longo do tempo. Esta anomalia podia muito bem ser uma predisposição genética que sempre existiu e que se deteriorou com o passar do tempo. Uma vez confirmada e explicada esta incapacidade ao casal, o passo seguinte consistiu em fazer com que o Luís e a Maria reajustassem o seu pensamento e as reacções um com o outro, num novo enquadramento. Este enquadramento permitiu-Ihes atribuir os seus problemas, em parte, à perturbação do Luís, a qual ajudou a pôr algumas coisas em perspectiva e a reduzir alguma da tensão na relação. Técnicas cognitivo-comportamentais, tais como a reestruturação de esquemas, foram usadas para ajudar ambos os parceiros a mudar o pensamento sobre as suas interacções, à luz desta nova informação. Tais técnicas cognitivas foram úteis para ajudar a Maria a não ficar tão zangada quando o Luís "distorcia” o que ela dizia. "Em vez de ver isto como uma forma de me manipular ou de me fazer parecer uma espécie de idiota, reestruturar o meu pensamento pareceu dispersar a minha raiva e permitiu que a nossa comunicação fluísse um pouco melhor."

\section{Discussão}

Por vezes, compreender a química cerebral e a forma como se relaciona com a cognição, a emoção e o comportamento é essencial para compreender os conflitos que ocorrem nas relações. Embora o caso do Luís e da Maria seja um exemplo extremo de défices neuronais, existem outros casos que são menos extremos e que não envolvem uma doença degenerativa, mas que reflectem um défice ou uma limitação mais funcional que pode contribuir para alguma disfunção na relação. É importante compreender que a química cerebral nos pode afectar de forma diferente, tornando-se mais difícil processar o pensamento e a emoção. Ser capaz de separar o que é deliberado daquilo que não é pode ser um enorme desafio e é também aquilo que torna a terapia neste domínio bastante árdua.

É importante compreender até que ponto o processo neurobiológico do corpo humano afecta as nossas relações e o modo como pode limitar a mudança que os casais fazem em terapia. A investigação futura nesta área provavelmente apenas irá revelar novas complexidades da actividade cerebral relativamente à cognição e à emoção e ao seu papel vital na interacção relacional. O debate contínuo sobre as dinâmicas específicas entre cognição e emoção e a sua neuroetiologia irá, possivelmente, continuar por algum tempo. Será importante para a investigação progredir para além da compreensão das simples dinâmicas interaccionais e focar-se na forma como a cognição e a emoção são efectivamente integradas no cérebro. 


\section{Referências bibliográficas}

Aron, A., Fisher, H., Mashek, D. J., Strong, G., Li, H., \& Brown, L. L. (2005). Reward, motivation, and emotion systems associated with early-stage intense romantic love. Journal of Neurophysiology, 94, 327-337.

Atkinson, B. J. (2005). Emotional intelligence in couples therapy: Advances from neurobiology and the science of intimate relationships. New York: Norton.

Damasio, A. (1994). Descartes'Error. New York: Grosset/Putnam.

Damasio, A. (1999). The Feeling of what Happens: Body and Emotion in the Making of Consciousness. New York: Harcourt.

Dattilio, F. M. (2010). Cognitive-behavior therapy with couples and families: A comprehensive guide for clinicians. New York: Guilford Press.

Dattilio, F. M. (in press). Examining the scope and concept of schema: Should we look beyond cognitive structures? Psychological Topics.

Gardner, H. (1985). The Mind's New Science: A History of the Cognitive Revolution - New York: Basic Books.

Goldstein, S., \& Thau, S. (2004). Integrating attachment theory and neuroscience in couple therapy. International Journal of Applied Psychoanalytic Studies, 1(3), 214-223.

Goleman, D. P. (1995). Emotional Intelligence: Why It Can Matter More Than IO for Character, Health and Lifelong Achievement. Bantam Books, New York.

Gottman, J. M. (1991). Predicting the longitudinal course of marriages, Journal of Marital and Family Therapy, 17, 3-7.

Kelly, G. A. (1955). The psychology of personal constructs. New York: Norton.

LeDoux, J. (1996). The emotional brain. New York: Simon \& Schuster.

LeDoux, J. (2000). Emotion circuits in the brain. Annual Review of Neuroscience, 23, 155-184.

Lewis, T., Amini, F., \& Lannon, R. (2002). A general theory of love. New York: Vintage Press.

Pert, C. B., Ruff, M. R., Weber, R. J., \& Herkenham, M. (1985). Neuropeptides and their receptors: A psychosomatic network. Journal of Immunology, 35(2), 30-35.

Pert, C. B., \& Snyder, S. H. (1973). Opiate receptor: Demonstration in nervous tissue. Science, 179, 1011-1014.

Pessoa, L. (2008). On the relationship between emotion and cognition. Nature Reviews/ Neuroscience, 9(2), 148-158.

Schore, A. N. (1994). Affect regulation and the origin of self: The neurobiology of emotional development. Mahwah, NJ: Erlbaum.

Schore, A. N. (2001). The effects of secure attachment relationships on right brain development, affect regulation and infant mental health. Infant Mental Health Journal, 22, 7-66.

Schore, A. M. (2003). Affect regulation and the repair of the self. New York: Norton.

Siegel, D. (1999). The developing mind. New York: Guilford Press.

Wagner, T. D., \& Phan, K. L. (2003). Valance, gender, and lateralization of functional brain anatomy in emotion: A meta-analysis of findings from neuroimaging. Neuroimage, 19(3), 513-531. 


\section{Le rôle du processus neurobiologiques en thérapie cognitive-comporte- mentale}

Récemment, la littérature professionnelle sur les relations de couple a porté sur l'effet que la génétique et la neurobiologie ont sur la dynamique interactionnel du couple. Une attention particulière a été accordée à savoir comme sont affectés les aspects émotionnels et comportementaux par les components neurobiologiques. Cet article fournit un bref aperçu de la littérature sur ce sujet et présente brève exemples illustratifs sur la validité des processus neuropsychobiologiques, en combinaison avec les techniques cognitives-comportementales, pour aider certain couples a s'occuper des problèmes relationnelles.

La discussion met en évidence des considérations futures pour la recherche et de développement dans ce domaine.

MOTS-CLÉS: Processus neurobiologiques; régulation émotionnel; génétique; amygdale.

\section{The role of neurobiological processes in couple cognitive-behavioral therapy}

Recently, the professional literature about couple relationships has been focused on the effect of genetics and neurobiology on interactional couple dynamics. Specific attention has been given to how emotional and behavioral patterns are affected by neurobiological components.

This article provides a brief overview of this emergent issue. It also enlightens how neuropsychobiological processes can be crucial, in combination with cognitivebehavioral techniques, for helping some couples to deal with relational problems. A discussion section provides considerations for future research and development.

KEY-WORDS: Neurobiological process; emotional regulation; genetics; amygdale. 